\title{
THE USE OF MUSIC AS AN ADJUVANT THERAPY FOR MENTAL ILLNESSES: A REVIEW
}

\author{
Keller Soares Ávila1, ORCID ID 0000-0003-0168-2982; Lara Santos Rocha1, ORCID ID 0000-0003-0984-2127; \\ Alexandre de Rezende Pinto², ORCID ID 0000-0003-2134-8770
}

\section{AFFILIATION}

(1) Federal University of Juiz de Fora (UFJF), Medical Student ${ }^{1}$

(2) Federal University of Juiz de Fora (UFJF), Master (MA), Professor of the Psychiatry Departament ${ }^{3}$

\section{MAIN AUTHOR'S INFORMATION}

Keller Soares Ávila; kellersavila@hotmail.com; University of Juiz de Fora's Medical School - Av. Eugênio do Nascimento, $s / n^{\circ}$ - Dom Bosco, Juiz de Fora - MG, Brazil.

\section{KEY-MESSAGES}

The use of music as an adjuvant therapy for different mental disorders in Psychiatry is recent and promising Music therapy is dynamic and versatile, and can be used actively, passively (or both) while treating psychiatric disorders

Most reviewed studies showed positive results with its use to treat several mental illnesses

Music therapy should be stimulated since it promotes comprehensive care for the patient, complementing conservative treatment

Future studies with greater samples are required to establish the best method regarding music therapy for each mental disease

\begin{abstract}
INTRODUCTION: The use of music therapy (MT) as an adjuvant treatment for different types of diseases is promising and valid, given the emotional and cognitive benefits that exposure to music (actively or passively) offers. This literature review aims to elucidate how MT can be used to complement the usual treatment of mental disorders, its best propaedeutics, and possible harms. METHOD: The guiding question for this review was "In people diagnosed with mental disorders, does MT as an adjuvant therapy offer better clinical results compared to traditional treatment?". The descriptors used on the search were "mental disorders", "music therapy" and "psychiatric rehabilitation", in MEDLINE, SciELO, and LILACS. The study was conducted in April 2021. Rigid inclusion and exclusion criteria were applied. RESULTS: The 15 studies selected for this review come from 9 countries. Most are controlled clinical trials from the United States. They present several benefits of using MT in mental disorders such as depression, anxiety, panic disorder, post-traumatic stress disorder, and schizophrenia, improving emotional control, cognitive ability, interpersonal relationships, and quality of life. DISCUSSION: MT shows strong positive results in the treatment of mental disorders in people of different ages, offers emotional relief, improved cognitive functions and interpersonal relationships, also reducing stress and depressive symptoms. In addition, it is a feasible therapy, with different applications, but it does not replace pharmacological treatment and psychotherapy. Few articles showed harmful effects of MT, observed only when it was associated with psychoactive drugs, generating unwelcome responses. CONCLUSION: Evidence suggests that MT is an excellent adjuvant therapy for the treatment of mental disorders with different clinical spectrums. Experiments with a larger sample size are required to elucidate the most effective technique and treatment duration for each mental disorder, considering individuality and the undeniable importance of pharmacotherapy and psychotherapy.
\end{abstract}




\section{INTRODUCTION}

Music therapy (MT) consists of the use of music, in a clinical context, for treatment, rehabilitation and promotion of an individual's health and well-being. It is a practice that, when individualized, allows the establishment of personalized goals, according to the needs of each person and the evaluation of a qualified music therapist ${ }^{1}$. Exposure to music, as simple as it is, such as listening to music, singing, or playing an instrument, is also considered a form of therapy and can help patients achieve the best therapeutical effects when a health professional is guiding this experience ${ }^{1}$. This form of therapy has generated positive results in several patients and their rehabilitation. However, MT should not have the ultimate goal of replacing conventional treatment, but to become a complementary one ${ }^{1}$.

Regarding the applicability of this therapy, recent studies have proven that MT improves motor and cognitive skills in patients with conditions of different degrees, such as those who suffered a stroke ${ }^{2}$, victims of firearm damage, chronic neurological diseases ${ }^{3}$, and, especially, mental and psychological disorders ${ }^{4}$.

Music is a complex phenomenon, which stimulates the activation of not only emotional and cognitive cortex areas but also motor ones, in addition to increasing the release of specific neurotransmitters, promoting change in the central nervous system ${ }^{5}$. Furthermore, knowing that the notion of health comprises a state of physical, mental, and social wellbeing (not just the absence of diseases) ${ }^{6}$, MT seems to be beneficial for health, as it helps to develop positive changes in the individual's mental state.

Several recent studies address the application of MT to treat diseases related to neurological degeneration, such as senile dementia ${ }^{7}$ and Parkinson's disease (PD) ${ }^{8}$. A recent noncontrolled intervention work analyzed the impacts of an eight-week MT program and technology-based music interventions among people with dementia. The intervention group was submitted to a larger number of sessions and showed a decrease in agitation and apathy when compared to the other group (submitted to fewer sessions) 7 . Furthermore, another article, a non-randomized clinical controlled trial, involving 13 people with $\mathrm{PD}$, noted an improvement in cognitive function, balance, and functional mobility with the use of MT, although these benefits were not maintained after the therapy ended ${ }^{8}$.

Despite this, these studies seem to be limited to neurological illnesses, exposing a gap in the literature concerning the use of this therapy specifically for mental disorders ${ }^{9-11}$. Thus, the use of MT in psychiatric rehabilitation and its benefits are not yet evident. What would be the optimal time for the exhibition, the type of music, the patient's position during the session, and any possible harms of musical adjuvant treatment are still unclear questions.

Hence, this literature review seeks to address such issues, guaranteeing a base material for future research on the use of MT as a complementary therapy for people with psychiatric syndromes. The main goal of this work is to gather information about the application of MT, the way it is performed, and the consequences of using it as an adjuvant treatment in people with mental disorders, evaluating the effectiveness, protocols, and response of patients in different studies.

Thus, the PICO strategy was implemented to create the guiding question for this article, which is "In people diagnosed with mental disorders, does MT as an adjuvant therapy to the main treatment offer better clinical results compared to the use of only traditional treatment (psychopharmacotherapy)?"

\section{METHOD}

This article is a literature review. Therefore, it seeks to help readers understand more about the subject in question through the search, selection, analysis, and interpretation of the literature previously produced and available. In the search stage, the databases of Latin American and Caribbean Literature in Health Sciences (LILACS) and International Literature in Health Sciences (MEDLINE) were consulted. The Scientific Electronic Library Online (SciELO) was examined as well.

The descriptors used in this review were chosen accordingly to the Health Sciences Descriptors (DeCS) and the Medical Subject Headings (MeSH): "mental disorders", "music therapy" and "psychiatric rehabilitation". They were combined with the boolean word "AND" as cited: "music therapy AND psychiatric rehabilitation" or "music therapy AND mental disorders". After the initial search, the articles were filtered while applicating the following inclusion criteria: be written in Portuguese or English, have the full text available online and have a publication date from 2016 up to April 19, 2021. The study was conducted in April 2021. The establishment of the language criteria intended to allow articles from all countries to be reviewed, considering English to be the main language used in the scientific field. Portuguese was included since it was the authors' mother language. The publication date was chosen to limit the analysis in this review to the most recent discoveries regarding MT.

Subsequently, the articles that passed this first selection were divided into two same-sized groups according to the appearance order. The titles and abstracts of each group were analyzed by one of the authors with broad experience in scientific methodology, and then, reanalyzed by another author. This process allowed for a second selection to occur, considering the exclusion criteria established for the present review.

The criteria for excluding an article were decided based on the guiding question and the PICO strategy, considering the specific population $(\mathrm{P})$, intervention (I), control (C), and outcome (O) addressed by this review. Therefore, the exclusion criteria were: addressing other therapies besides MT and pharmacological and psychological treatment (dance, yoga, meditation, etc.); having the majority of the sample composed of symptomatic people who do not have a specific psychiatric diagnosis; having the majority of the sample 
composed of patients with diseases addressed mainly in Neurology (senile dementia, Alzheimer's disease, PD, etc.); having the majority of the sample composed of patients with non-psychiatric disorders (chronic kidney disease, poststroke, healthy people, etc.); studies without results; editorials; reviews; not having human beings as the object of study; duplicates (only one copy was considered) or not being available for free. Paid articles that were available for free through the ScienceDirect platform were kept for further analysis since they could be accessed through the login provided by the authors' home institution.

After the second selection, the remaining articles were all read thoroughly by two of the authors together and analyzed for this review, to obtain information from each article, such as type of study, main objectives, sample size, type of MT applied, and main results.

\section{RESULTS}

Initially, 1,914 relevant articles were obtained in the search. After the application of the inclusion criteria, 457 articles were submitted to the second selection, considering the exclusion criteria, which eliminated 442 articles. The 15 remaining articles were considered for this review. The selection of the articles is illustrated in more detail in the flowchart of Figure 1, based on the PRISMA 2020 protocol flow diagram.

The fifteen articles selected were read minutely to allow for their detailed analysis. Most of the studies were controlled clinical trials $(n=9)^{10,12-19}$, followed by observational studies $(n=6)^{20-25}$
Chemical Dependency $(n=3)^{17,18,23}$, and Multiple Diseases ( $n$ $=4)^{10,19,24,25}$. The last group consisted of articles that dealt with more than one disorder simultaneously.

Figure 2 also presents an overview of the information obtained from each study. All 3 included in the "Depression" group of articles used passive MT to treat depression and had mainly positive results ${ }^{12,13,20}$. Passive MT was also beneficial for patients diagnosed with panic disorder, reducing depressive symptoms ${ }^{14}$. Both works addressing MT in the treatment of post-traumatic stress disorder had active MT as their intervention, providing positive outcomes ${ }^{15,21}$. Only one article discussed social anxiety disorder, in which active MT seemed to reduce hyperarousal ${ }^{16}$. Schizophrenia was another mental illness that presented positive results when treated with MT, even though there was not a significant improvement in quality of life scores ${ }^{22}$. Passive MT also had positive impacts on chemically dependent people, reducing stress and the probability of relapse ${ }^{17,18,23}$. The "Multiple Diseases" group presented some positive results when comparing MT to the usual treatment, but some benefits were not statistically significant ${ }^{10,19,24,25}$. MT seems to be safe, since no harms were observed in any of the studies, except when MT was associated with psychoactive substances. Regarding their original countries, the distribution showed a predominance of studies from the United States of America $(n=5)^{14,15,17,18,21}$ and the United Kingdom $(n=3)^{10,19,20}$. Denmark ${ }^{12}$, China ${ }^{13}$, South Korea $^{22}$, Brazil ${ }^{23}$, Canada ${ }^{24}$, and Germany ${ }^{25}$ also participated in the analysis, each of them with only one selected article $(n=$ 6 ). In addition, one was a result of a partnership between Israel and the United States of America $(n=1)^{16}$. In terms of scientific production related to the subject addressed, Europe and North America seem to be more active.

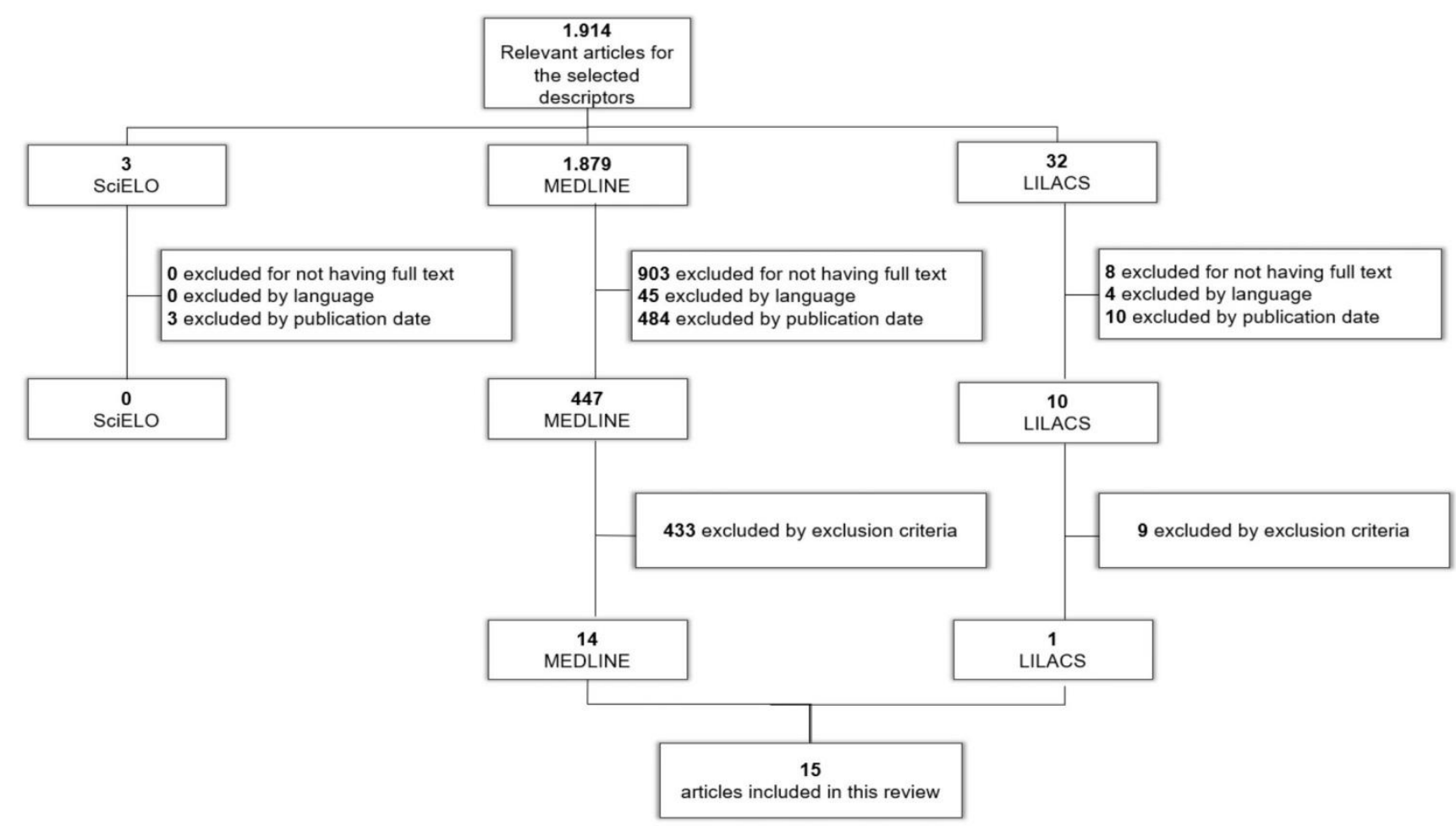

Figure 1: The Selection of Articles

Figure 1 shows a flowchart that explains how the 15 articles for this review were selected and their original sources, as well as how many articles were excluded. Made by the authors, 2021. 


\begin{tabular}{|c|c|c|c|c|c|c|c|}
\hline Study Object & Article Title & Journal and Year & Type of Study & Main Objectives & Sample Size & $\begin{array}{l}\text { Type of Music } \\
\text { Therapy Applied }\end{array}$ & Main Results \\
\hline \multirow{3}{*}{ Depression } & $\begin{array}{c}\text { A pilot study on high amplitude low } \\
\text { frequency-music impulse } \\
\text { stimulation as an add-on treatment } \\
\text { for depression }\end{array}$ & $\begin{array}{l}\text { Brain and Behavior, } \\
\text { Volume } 9 \text {, Issue } 10, \\
2019\end{array}$ & $\begin{array}{l}\text { Randomised } \\
\text { controlled trial. }\end{array}$ & $\begin{array}{c}\text { Determine the feasibility, efficacy, and } \\
\text { potential side effects of High Amplitude } \\
\text { Low Frequency-Music Impulse Stimulation } \\
\text { (HALF-MIS), used as an add-on treatment } \\
\text { for depression. }\end{array}$ & $\begin{array}{l}38 \text { patients } \\
\text { diagnosed with } \\
\text { depression. }\end{array}$ & Passive. & $\begin{array}{l}\text { HALF-MIS treatment seems to give beneficial effect as an add- } \\
\text { on treatment for depression. HALF-MIS appears to be a safe } \\
\text { and effective add-on treatment for depression. }\end{array}$ \\
\hline & $\begin{array}{c}\text { Effects of music therapy on major } \\
\text { depressive disorder: study of } \\
\text { prefrontal hemodynamic functions } \\
\text { using } \text { fNIRS }^{13}\end{array}$ & $\begin{array}{c}\text { Psychatry Research, } \\
\text { Volume 275, Pages 86- } \\
93,2019\end{array}$ & $\begin{array}{l}\text { Randomised } \\
\text { controlled trial. }\end{array}$ & $\begin{array}{c}\text { Employ near-infrared spectroscopy (NIRS) } \\
\text { to explore the effects of music therapy on } \\
\text { brain activity in mild or moderate major } \\
\text { depressive disorder patients and to } \\
\text { illustrate the potential mechanism of music } \\
\text { therapy. }\end{array}$ & $\begin{array}{c}30 \text { patients } \\
\text { diagnosed with major } \\
\text { depressive disorder. }\end{array}$ & Passive. & 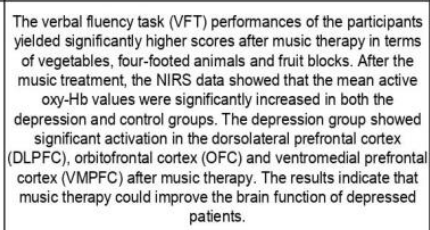 \\
\hline & $\begin{array}{c}\text { The hidden therapist: evidence for a } \\
\text { central role of music in psychedelic } \\
\text { therapy } y^{20}\end{array}$ & \begin{tabular}{|c|} 
Psychopharmacology, \\
Volume 235, Pages 505- \\
519,2018
\end{tabular} & Observational study. & $\begin{array}{l}\text { Assess the influence of music on the acute } \\
\text { experience and clinical outcomes of } \\
\text { psychedelic therapy. }\end{array}$ & \begin{tabular}{|c|}
19 patients \\
undergoing \\
psychedelic therapy \\
with psilocybin for \\
treatment-resistant \\
depression.
\end{tabular} & Passive. & $\begin{array}{l}\text { Patients' experience of the music, but not drug (psilocybin) } \\
\text { intensity, was predictive of reductions in depression } 1 \text { week } \\
\text { later, suggesting that music plays a central mediating role in } \\
\text { psychedelic therapy. Unwelcome responses were also noted, } \\
\text { but they were less common than positive responses. }\end{array}$ \\
\hline Panic Disorder & $\begin{array}{c}\text { Psychological treatment of } \\
\text { comorbid asthma and panic } \\
\text { disorder in Latino adults: Results } \\
\text { from a randomized controlled trial }{ }^{14}\end{array}$ & \begin{tabular}{|c|} 
Behavior Research and \\
Therapy, Volume 87, \\
Pages 142-154, 2016
\end{tabular} & $\begin{array}{l}\text { Randomised } \\
\text { controlled trial. }\end{array}$ & $\begin{array}{c}\text { Compare cognitive behavior } \\
\text { psychophysiological therapy (CBPT) to } \\
\text { music and relaxation therapy (MRT), which } \\
\text { included listening to relaxing music and } \\
\text { paced breathing at resting respiration } \\
\text { rates, in patients with asthma and panic } \\
\text { disorder. }\end{array}$ & $\begin{array}{l}53 \text { Latino adults with } \\
\text { asthma and panic } \\
\text { disorder. }\end{array}$ & Passive. & $\begin{array}{l}\text { Both groups showed improvements in panic disorder severity, } \\
\text { asthma control, and several other anxiety and asthma outcome } \\
\text { measures from baseline to post-treatment and 3-month follow- } \\
\text { up. CBP showed an advantage over MRT for improvement in } \\
\text { acherence to inhaled corticosteroids. Improvements in panic } \\
\text { disorder severity were mediated by anxiety sensitivity in CBPT } \\
\text { and by depression in MRT, although earlier levels of these } \\
\text { mediators did not predict subsequent improvements. }\end{array}$ \\
\hline \multirow[b]{2}{*}{$\begin{array}{l}\text { Post-traumatic } \\
\text { Stress Disorder }\end{array}$} & \begin{tabular}{|l|} 
Music-intruction intervention for \\
treatment of post-traumatic stress \\
disorder: a randomized pilot study
\end{tabular} & \begin{tabular}{|c|} 
BMC Psychology, \\
Volume 6, Issue 1, \\
Article Number 60,2018
\end{tabular} & $\begin{array}{l}\text { Randomised } \\
\text { controlled trial. }\end{array}$ & \begin{tabular}{|l|} 
Examine the feasibility and potential \\
effectiveness of an active, music- \\
instruction intervention in improving \\
psychological health and social functioning \\
among Veterans suffering from moderate \\
to severe Post-traumatic stress disorder \\
(PTSD).
\end{tabular} & $\begin{array}{c}40 \text { veterans receiving } \\
\text { routine care for } \\
\text { PTSD symptoms at } \\
\text { the Zablocki VA } \\
\text { Medical Center in } \\
\text { Milwaukee. }\end{array}$ & Active. & $\begin{array}{l}\text { The results of this pilot study suggest that Guitars for Vets is a } \\
\text { safe and potentially effective intervention to improve PTSD and } \\
\text { depressive symptoms among veterans with moderate to severe } \\
\text { PTSD. }\end{array}$ \\
\hline & $\begin{array}{l}\text { Collaborative Songwiting } \\
\text { Intervention for Veterans with Post- } \\
\text { Traumatic Stress Disorder" }\end{array}$ & $\begin{array}{c}\text { The Journal of } \\
\text { Altemative and } \\
\text { Complementary } \\
\text { Medicine, }, \text { olume } 26, \\
\text { Issue 3, Pages 198-203, } \\
2020\end{array}$ & Observational study. & $\begin{array}{l}\text { Determine the acceptability and feasibility } \\
\text { of collaborative songwiting in a clinical } \\
\text { setting and determine if there would be any } \\
\text { reduction in reported symptoms of PTSD } \\
\text { (specifically yyperarousalland depression } \\
\text { as well as a potential improvement in } \\
\text { participant's physical activity and sleep (as } \\
\text { measured by a Fitbit) among the veterans } \\
\text { undergoing the intervention. }\end{array}$ & $\begin{array}{l}10 \text { veterans } \\
\text { diagnosed with } \\
\text { PTSD }\end{array}$ & Active and passive. & $\begin{array}{l}\text { Participants reported that the intervention was helpful and } \\
\text { relevant to them, and most participants (95\%) would refer } \\
\text { others to this treatment. Collaborative songwriting reduced } \\
\text { participant's PTSD symptoms, specifically the Numbing and } \\
\text { Hyperarousal subscales. Depressive symptoms and stress } \\
\text { reactivity also marginally decreased. There was no significant } \\
\text { change in physiological data (i.e., sleep, no. of steps) from pre- } \\
\text { to postintervention. }\end{array}$ \\
\hline $\begin{array}{l}\text { Social Anxiety } \\
\text { Disorder }\end{array}$ & \begin{tabular}{|c|} 
Gaze-Contingent Music Reward \\
Therapy for Social Anxiety Disorder: \\
A Rabdomized Controlled Trial
\end{tabular} & \begin{tabular}{|l} 
The American Journal of \\
Psychiatry, Volume 174, \\
Issue 7, Pages $649-656$, \\
2017
\end{tabular} & $\begin{array}{l}\text { Randomised } \\
\text { controlled trial. }\end{array}$ & $\begin{array}{c}\text { Examine the efficacy of a novel gaze- } \\
\text { contingent music reward therapy for social } \\
\text { anxiety disorder designed to reduce } \\
\text { attention dwelling on threats. }\end{array}$ & \begin{tabular}{|c|}
40 patients \\
diagnosed with social \\
anxiety disorder.
\end{tabular} & Passive. & $\begin{array}{l}\text { Gaze-contingent music reward therapy yielded greater } \\
\text { reductions of symptoms of social anxiety disorder than the } \\
\text { control condition on both clinician-rated and self-reported } \\
\text { measures. }\end{array}$ \\
\hline Schizophrenia & $\begin{array}{c}\text { The Effectiveness of the Nanta- } \\
\text { Program on Psychiatric Symptoms, } \\
\text { Interpersonal Relationships and } \\
\text { Quality of Life in Forensic Inpatients } \\
\text { with Schizophrenia }\end{array}$ & $\begin{array}{c}\text { Archives of Psychiatric } \\
\text { Nursing, Volume 31, } \\
\text { Issue 1, Pages 93-98, } \\
2017\end{array}$ & Observational study. & $\begin{array}{l}\text { Examine the effectiveness of the Nanta- } \\
\text { program on psychiatric symptoms, } \\
\text { interpersonal relationships, and quality of } \\
\text { life (QoL) in forensic inpatients with } \\
\text { schizophrenia (SPR). }\end{array}$ & $\begin{array}{l}38 \text { forensic inpatients } \\
\text { with SPR from South } \\
\text { Korea. }\end{array}$ & Active. & $\begin{array}{l}\text { The experimental group showed significant improvements in } \\
\text { psychiatric symptoms and slight improvement in interpersonal } \\
\text { relationships after } 12 \text { weeks of group music therapy. There was } \\
\text { no significant difference in QoL change between the two } \\
\text { groups. These findings indicate that the Nanta-program is an } \\
\text { effective intervention program for improving psychiatric } \\
\text { symptoms and interpersonal relationships of prisoners with } \\
\text { SPR. }\end{array}$ \\
\hline \multirow{3}{*}{$\begin{array}{l}\text { Chemical } \\
\text { Dependency }\end{array}$} & $\begin{array}{c}\text { Effect of music therapy on stress in } \\
\text { chemically dependent people: a } \\
\text { quase-experimental study }\end{array}$ & \begin{tabular}{|c|} 
Revista Latino- \\
Americana de \\
Enfermagem, Volume \\
27: e3115, Epub 2019
\end{tabular} & Observational study. & $\begin{array}{l}\text { Evaluate the effect of music therapy on the } \\
\text { stress of chemically dependent people. }\end{array}$ & $\begin{array}{c}18 \text { chemically } \\
\text { dependent people } \\
\text { undergoing } \\
\text { treatment. }\end{array}$ & Passive. & $\begin{array}{l}\text { After } 60 \text { minutes of intervention, there was a statistically } \\
\text { significant reduction in mean salivary cortisol levels }(p<0.001) \text {. } \\
\text { A reduction was also noted after } 120 \text { minutes, but without } \\
\text { statistical significance }(p=0.139) \text {. }\end{array}$ \\
\hline & \begin{tabular}{|c|}
$\begin{array}{l}\text { Relapse prevention: Using sound to } \\
\text { reduce the probability of recidivism } \\
\text { and suffering following } \\
\text { detoxification }\end{array}$ \\
\end{tabular} & \begin{tabular}{|c|} 
Medical Hypotheses, \\
Volume 118, Pages 84 - \\
91,2018 \\
\end{tabular} & $\begin{array}{l}\text { Randomised } \\
\text { controlled trial. }\end{array}$ & $\begin{array}{c}\text { Determine if our sound intervention could } \\
\text { reduce the probability of relapse in recently } \\
\text { detoxified subjects. }\end{array}$ & 116 patients. & Passive. & $\begin{array}{l}\text { Listening to the Experimental } C D \text {, per-protocol, compared to the } \\
\text { Control } C D \text {, also per-protocol, significantly reduced the } \\
\text { probability of relapse during the } 90 \text {-days of this study. }\end{array}$ \\
\hline & $\begin{array}{l}\text { The acute effect of pleasurable } \\
\text { music on craving for alcohol: A pilot } \\
\text { crossover study }\end{array}$ & $\begin{array}{l}\text { Journal of Psychiatric } \\
\text { Research, Volume } 90, \\
\text { Pages } 143-147,2017\end{array}$ & $\begin{array}{l}\text { Randomised } \\
\text { controlled trial. }\end{array}$ & $\begin{array}{l}\text { Evaluate the efficacy of listening to } \\
\text { personally pleasing or moving music on } \\
\text { reducing craving in abstinent alcoholics }\end{array}$ & $\begin{array}{c}12 \text { patients with } \\
\text { Alcohol Use Disorder } \\
\text { on a residential } \\
\text { substance } \\
\text { rehabilitation unit. }\end{array}$ & Passive. & $\begin{array}{l}\text { Using a mixed model to analyze the crossover design, the } \\
\text { music intervention was found to have a statistically significant } \\
\text { advantage in craving reduction compared to the noise control. } \\
\text { Our results indicate that personally pleasing music might have a } \\
\text { role in augmenting substance use disorder treatment via } \\
\text { craving reduction. }\end{array}$ \\
\hline \multirow{4}{*}{ Multiple Diseases } & $\begin{array}{c}\text { MAP: Personalized Receptive } \\
\text { Music Therapy Intervention to } \\
\text { Improve the Affective Well-being of } \\
\text { Youth Hospitalized in a Mental } \\
\text { Health Unit }{ }^{24}\end{array}$ & \begin{tabular}{|} 
Journal of Music \\
Therapy, Volume 56, \\
Issue 4, Pages 381-402, \\
2019
\end{tabular} & Observational study. & $\begin{array}{c}\text { Assess the mood-enhancing potential of } \\
\text { participation in Montage Audio } \\
\text { Personnalisé en Musicotherapie Réceptive } \\
\text { (MAP) sessions delivered by a music } \\
\text { therapist in an in-patient mental health } \\
\text { facility for children and adolescents using } \\
\text { short standardized self-reported } \\
\text { questionnaires. }\end{array}$ & $\begin{array}{l}20 \text { participants aged } \\
9-17 \text { years old, } \\
\text { mainly girls. }\end{array}$ & Passive. & $\begin{array}{l}\text { Results indicated that the average levels of general negative } \\
\text { affect and state anxiety reported by participants decreased by a } \\
\text { statistically significant margin from pre- to post-MAP sessions. }\end{array}$ \\
\hline & $\begin{array}{l}\text { The effects of music therapy on the } \\
\text { interaction of the self and emotions. } \\
\text { An interim analysis }{ }^{25}\end{array}$ & $\begin{array}{c}\text { Complementary } \\
\text { Therapies in Medicine, } \\
\text { Volume 4, Pages } 61-66, \\
2018\end{array}$ & Observational study. & $\begin{array}{l}\text { Assess the interplay of personality } \\
\text { dimensions and emotoon modulation } \\
\text { strategies in patients treated with music } \\
\text { therapy versus patients without music } \\
\text { therapy. }\end{array}$ & $\begin{array}{c}\text { Data from } 137 \\
\text { patients in a general } \\
\text { psychiatric hospital. }\end{array}$ & Active. & $\begin{array}{l}\text { Use of Music for Emotion modulation in Everyday Life (UofM) } \\
\text { can help patients solve problems and have funn. Music therapy } \\
\text { helps to recognize and to improve patients' self-sufficiency and } \\
\text { may lead to a change of personality dimensions resources and } \\
\text { to use music as an important medium for emotion modulation, } \\
\text { especially for cognitive } \\
\text { processing. }\end{array}$ \\
\hline & $\begin{array}{c}\text { A randomised controlled pilot and } \\
\text { feasibility study of music therapy for } \\
\text { improving the quality of life of } \\
\text { hospice inpatients }\end{array}$ & $\begin{array}{l}\text { BMC Paliative Care, } \\
\text { Volume } 17, \text { Article } \\
\text { Number } 125,2018\end{array}$ & $\begin{array}{l}\text { Randomised } \\
\text { controlled trial. }\end{array}$ & $\begin{array}{l}\text { Determine the feasibility of a randomised } \\
\text { controlled trial to evaluatet the } \\
\text { effectiveness of music therapy for } \\
\text { improving the QoL of hospice inpatients, } \\
\text { as measured by the McGill Quality of Life } \\
\text { questionnaire. }\end{array}$ & $\begin{array}{l}51 \text { patients from an } \\
\text { inpatient hospice. }\end{array}$ & Active. & $\begin{array}{l}\text { The difference between the groups was non-significantly in } \\
\text { favour of music therapy, although there was a notable } \\
\text { improvement in existential well-being for the music therapy } \\
\text { group compared to the control group. }\end{array}$ \\
\hline & 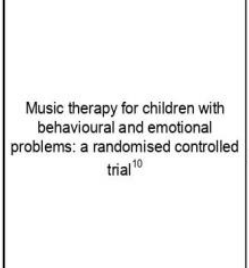 & \begin{tabular}{|c|} 
Joumal of Child \\
Psychology and \\
Psychiatry, Volume 58, \\
Issue 5, Pages 586-594, \\
2017
\end{tabular} & $\begin{array}{l}\text { Randomised } \\
\text { controlled trial. }\end{array}$ & $\begin{array}{l}\text { Assess how music therapy would affect } \\
\text { communicative and interactional skills } \\
\text { (measured by parental and self-erporting of } \\
\text { the Social Skills Improvement System } \\
\text { Rating Scales), self-esteem (measured } \\
\text { using the Rosenberg Self-Esteem Scale) } \\
\text { and depressive symmtoms (measured } \\
\text { using the Centre for Epidemiological } \\
\text { Studies Depression Scale for Children), } \\
\text { social functioning (measured using the } \\
\text { Child Behaviour Checklist) and family } \\
\text { functioning (assessed using the Family } \\
\text { Assessment Device. }\end{array}$ & $\begin{array}{l}251 \text { children with } \\
\text { emotional, behavioral } \\
\text { and development } \\
\text { difficulties registered } \\
\text { in Community care } \\
\text { facilities in Northern } \\
\text { Ireland. }\end{array}$ & Active. & $\begin{array}{l}\text { There was no significant difference for the child Social Skills } \\
\text { Improvement System Rating Scales (SSIS) at week } 13 \text { or for } \\
\text { the guardian SSIS. However, for participants aged } 13 \text { and over } \\
\text { in the intervention group, The child SSIS communication was } \\
\text { significantly improved but not the guardian SSIS. Overall, self- } \\
\text { esteem was significantly improved and depression scores were } \\
\text { significantly lower at week } 13 \text {. There was no significant } \\
\text { difference in family or social functioning at week } 13 \text {. }\end{array}$ \\
\hline
\end{tabular}

Figure 2: Group of articles

Figure 2 shows how the 15 selected articles for this review were divided in 7 groups, according to the mental disorder that was treated using music therapy in each study. Made by the authors, 2021. 
As for the publication period, only one article was published in $2020(n=1)^{21}$, four in $2019(n=4)^{12,13,23,24}$, five in $2018(n$ $=5)^{15,17,19,20,25}$, four in $2017(\mathrm{n}=4)^{10,16,18,22}$ and one in 2016 $(n=1)^{14}$. Since 2016, scientific interest in MT as an adjuvant therapy for mental disorders has increased, with a significant drop in 2020, probably due to the pandemic of COVID-19, which turned sciential efforts towards studying this emerging disease.

After reading the texts, a recurrence of specific diseases was noted. Thus, Figure 2 was organized, dividing the articles into 7 groups, named according to each one treated by MT. As a result, 7 groups were formed, with the respective names: Depression $(n=3)^{12,13,20}$, Panic Disorder $(n=1)^{14}$, Post-Traumatic Stress Disorder $(n=2)^{15,21}$, Social Anxiety Disorder $(n=1)^{16}$, Schizophrenia $(n=1)^{22}$,

\section{DISCUSSION}

Psychiatry is a medical field that deals with challenging diagnoses in clinical practice since psychiatric illnesses are characterized by the combination of symptoms, subjective issues presented by the patient, and signs of different intensities, which must be detected by the examiner. In addition, there are no complementary and effective tests to characterize the specific disease of the patient ${ }^{26}$. These factors, therefore, increase the difficulty of choosing an appropriate therapy, which varies with the disease, the chances of its effectiveness, and the patient's tolerability, given the individuality of each case.

Until the mid-1970s, when the Psychiatric Reform process began in Brazil, the mental health care model was primarily hospital-centered, with hospitalization and pharmacotherapy being overvalued at the expense of more humanized care techniques ${ }^{27}$. Over the years, this model has been proven to be outdated and incomplete, with high rates of recurrence, and unable to promote holistic well-being to the patient, in contrast to the latest World Health Organization's definition of health ${ }^{6}$. Furthermore, it was evident that it did not provide the sick with emotional restructuring and social reintegration; instead, it drifted them apart from common life and their right to exercise their citizenship.

Thus, Brazil's psychiatric care model has changed, focusing on deinstitutionalization and including more humanized and integrative practices for mental health patients ${ }^{27}$. Along with this, an increasing number of studies related to integrative and complementary therapies in Psychiatry has been carried out. Although many of them consist of punctual research with small samples and a low level of control of variables, many randomized clinical trials, with a higher level of scientific evidence, have emerged to prove the effectiveness of several complementary therapies, such as MT, play therapy and therapy through dance ${ }^{4}$.

In regard to $\mathrm{MT}$, it stands out as a promising treatment to expand the range of possibilities when it comes to adjuvant therapies for mental disorders, to complement - and not replace - pharmacotherapy and psychotherapy, which are proven to be essential for the mental health care process.

\section{Depression}

Depression (ICD 10 - F32) is a disorder that affects a considerable part of the world population and is determined by the reduced interest in practicing daily activities, the persistence of a low mood, and the reduction of pleasure ${ }^{28}$, which can be addressed mainly by psychopharmacology and psychotherapy ${ }^{13}$. The application of MT showed positive impacts in all three studies analyzed, regardless of the chosen methodology and sample size - which, in general, was small.

It is interesting to emphasize the versatility of MT since there are different forms of application based on two premises: stimulating the patient's creativity (allowing him to participate actively in the composition of songs) and ensuring that he is exposed to songs selected by specialists to generate a specific emotion ${ }^{13}$. Thus, although the approach may be different within varieties of these two premises, the effects of MT on people with depression were, in general, positive.

Two articles stand out in terms of the methodology applied. The first one ${ }^{12}$ randomized 38 patients with depression. The control group underwent the usual treatment for the disease while the intervention group was treated with the same treatment plus Vibroacusticotherapy (VAT), more specifically, "High Amplitude Low Frequency - Music Impulse Stimulation (HALF-MIS)". This therapy submits them to musical sessions synchronized with vibrations applied directly to the body, providing relaxation, reducing stress, and improving mood through the stimulation of Pacini's corpuscles, generating afferent vagal stimuli to the nucleus of the solitary tract, in the bulb, which will proceed to the posteromedial ventral thalamic nucleus and will be distributed to different areas of the brain cortex. This stimulus proved to be decisive in the improvement of humoral and somatic symptoms in depression, and the patients in the intervention group scored lower on the Hamilton Depression Rating Scale (HAMD) - showing improvement in depression -, compared to the control group.

The second article addresses the oxygenation of brain areas before and after MT was offered to right-handed people (15 healthy and 15 with major depressive disorder) in a nonrandomized controlled clinical test ${ }^{13}$. After a period of weekly exposure to MT (receptive, only), depressed patients showed significant improvement in psychiatric tests that rated verbal fluency as well as in the Hamilton test ${ }^{13}$. In addition, the article offered another important result in agreement with previous literature ${ }^{29}$ : brain monitoring has elucidated some hypofunctional areas in the pre-treatment phase in the depressed group - dorsolateral prefrontal, ventromedial prefrontal, and orbitofrontal cortices - possibly responsible for depressive symptoms such as the difficulty in organizing plans, maintaining a stable behavior, regulating emotions, reacting to external stimuli and complex learning ${ }^{13}$.Therefore, although these two studies have a small sample and use specific MT methods, it was evident that the activation of several areas of the cerebral 
cortex promoted consequent improvement of symptoms, such as emotional control, cognitive skills, and reduction of anxiety, providing better social interaction as well.

It is important to report that, despite these benefits being elucidated, the studies had as the main limitation the small sample size ${ }^{12,13}$. There is still a lack of randomized research in the literature with larger samples and strict control of the used medications. This is necessary to avoid adverse effects and negative symptoms generated by an association of MT and pharmacotherapy, such as what was reported in an article, in which patients using psilocybin - a psychoactive derived from mushrooms - were submitted to MT, to simulate different emotions and provide relief and improvement of depressive symptoms ${ }^{20}$. However, the association, due to individual sensitivity, was positive for some and disastrous for others, precisely because of the incongruity of the musical effect with the medicament, at certain times.

\section{Panic Disorder}

As for panic disorder (ICD 10 - F41.0), the only article selected on this topic used MT as a strategy for relaxing patients in the intervention group of a randomized study, while the control group was submitted to cognitive behavioral therapy - with asthma education for patients panic control therapy and progressive muscle relaxation ${ }^{14}$. Although positive results were noted in both clusters, such as the reduction in anxiety, depressive symptoms, the severity of the panic disorder and asthma, it was noticed that people in the control group, after therapy, had greater adherence to inhaled corticosteroids therapy, important for the treatment of asthma, while the one that underwent MT obtained better results in reducing depressive symptoms.

It is important to note that this article was well developed, and the method was fully elucidated and discussed statistically, but its results should be taken with a grain of salt since it did not address the use of MT in patients with only panic disorder. After all, the entire selected sample (which was small) was of Latin descent and had asthma as comorbidity. Therefore, there is a lack of studies that, in fact, relate MT and this psychiatric disease specifically.

\section{Post-traumatic Stress Disorder}

Post-traumatic stress disorder (ICD 10 - F43.1) is a common mental disorder, developed after traumatic situations, such as an episode of violence, death, or war ${ }^{15}$. In the United States of America (USA), military or ex-military personnel (veterans) are a social group especially affected by this condition, resulting in loss of quality of life and isolation, in addition to lower life expectancy compared to the general population. The application of MT in this illness proved to be efficient in two of the analyzed studies.

As previously stated, MT is a broad therapy, which can be applied in many ways. Hence, learning to play an instrument, listening daily to a specific playlist or even songwriting can be considered MT. Guitar lessons implemented for 6 weeks proved to significantly reduce symptoms of post-traumatic stress disorder (PTSD) and depression in a randomized clinical study with 40 veterans diagnosed in the USA ${ }^{15}$. However, there was no statistically significant improvement in cognitive skills, social function, and quality of life.

Prolonged Exposure Therapy (PTE), in which the individual is subjected to situations or reminders of the trauma that occurred, to facilitate their overcoming, is a modality of psychotherapy that has had positive results in studies with PTSD patients, suggesting that PTE is more efficient than simple counseling ${ }^{30}$. Based on this result, 10 veterans diagnosed with PTSD participated in an intervention based on PTE, which included composing a song - regarding the trauma experienced - with a professional songwriter, recording it, and listening to it daily for 5 weeks. This intervention proved to be effective in reducing symptoms of numbness, hyperarousal, depression, and reactivity to stress $^{21}$.

Both articles were conducted with a small sample and the results were measured using self-assessment questionnaires. In addition, the samples, although representative of the US military's social cluster, were composed almost exclusively of white men. Therefore, it is important to carry out more studies with larger and more diverse samples to guarantee the veracity of the findings and benefits of MT for patients with PTSD.

\section{Social Anxiety Disorder}

Social anxiety disorder (ICD 10 - F40.1) is a mental disorder characterized by a phobia of social interactions, associated with an irrational fear of being judged, causing embarrassment and fear, affecting the patient's quality of life. In this disease, an important characteristic is the feeling of being constantly observed and judged by the individuals around you ${ }^{31}$.

An original study published in The American Journal of Psychiatry in 2017 used MT as a form of "psychological training" to adjust the attention focus in 40 patients diagnosed with social anxiety disorder (SAD). In the experiment, patients underwent MT sessions, in which they were told to observe a set of faces projected on a wall, arranged randomly. Some faces represented "threat" disgusted faces - and others represented "neutrality" neutral faces. The control group observed the projection on the wall to the sound of pleasant music of their choice, without interruption. The experimental one, on the other hand, observed the faces freely, but the music was interrupted when the gaze was focused on one of the "threatening" faces. At the end of the study, there was a considerable difference between the groups, with a more significant improvement in SAD symptoms (assessed by the Liebowitz Social Anxiety Scale and Social Phobia Inventory questionnaires) in the experimental cluster, precisely due to the conducted training, reducing the exaggerated focus on "threats" and using music as a positive reward ${ }^{16}$.

Although this innovative article suggests that MT may be 
useful to treat SAD, it is important to consider the study's limitations. First of all, the use of the eye-tracking instrument was rather expensive because it is a new and specific technology. Also, it was necessary to exclude patients with eyesight issues from the study, since they were unable to reach good levels of calibration with the machine. The study did not observe if the reduction of the symptoms was sustained after a long period, so it is still not explicit if the therapy is useful in the long term ${ }^{16}$.

\section{Schizophrenia}

Schizophrenia (ICD 10 - F20) is a serious mental disorder that usually starts manifesting around the age of 20 , in the form of psychiatric outbreaks. Symptoms such as restlessness, hallucinations, discouragement, maladjusted reactions to sad or happy stimuli and persecutory manias are common ${ }^{32}$.

Concerning this disorder, an experiment carried out in 2014 with South Korean prisoners diagnosed with schizophrenia evaluated 3 main aspects related to the health-disease process before and after twelve sessions of MT: psychiatric symptoms, interpersonal relationships, and quality of life. Regarding symptoms, several items were considered in the pre- and post-experiment questionnaires, including anxiety, depression, somatic symptoms, positive symptoms (mental disorganization, delusion of grandeur, hallucinations), negative symptoms (blunted affect, motor delay), hostility, excessive suspicion, and active symptoms (excitement, tension, mannerisms-posture). The assessment of interpersonal relationships included items such as personal satisfaction, communication, self-esteem, sensitivity, openness, kindness, and empathy. Finally, the questionnaire assessing quality of life evaluated items such as dissatisfaction, physical and mental function, and emotional control. The experiment was carried out with active MT, in which the participants used traditional Korean percussion instruments to create rhythms and sound patterns, conducted by a music therapist. The results were positive and significant for psychiatric symptoms, especially the reduction of active symptoms and promotion of interpersonal relationships, with no improvement in the assessment of quality of life 22 .

Once again, these results reveal the promising character of adjuvant MT in disorders that impair social interaction, showing that this therapy can be a mechanism to promote socializing and the exchange of experiences. In addition, the active method appears to be effective in reducing stress, tension, and hyperarousal.

\section{Chemical Dependency}

Chemical dependency (ICD 10 - F19) is a mental and behavioral disorder that can occur due to the abusive use of psychoactive substances, known for promoting dopaminergic stimuli in the brain reward circuit - nucleus accumbens + ventral tegmental area ${ }^{18}$. This condition can be approached by MT in different ways. Assuming that music can stimulate the release of dopaminergic neurotransmitters, scientists hypothesize that it could act as a substitution mechanism for the drug when desire/withdrawal emerges. This idea was applied in two of the analyzed studies: music was able to promote significant reductions in the level of desire both momentarily ${ }^{18}$ and in the long term (90 days), in this case, associated with subliminal messages of positive stimulus ${ }^{17}$.

Nonetheless, stress is a major stimulator of drug use as an escape mechanism by drug addicts. Cortisol's presence in the patient's blood can be inversely associated with preventing relapse, since it is a stress bioindicator. In a study conducted in Brazil, the cortisol levels of patients submitted to a 60-minute passive MT session decreased. That indicated a stress reduction and showed a beneficial effect of music exposure as a potential intervention to diminish the chances of relapse ${ }^{23}$.

\section{Multiple Diseases}

When MT was used in people with different psychiatric disorders, it confirmed, similarly to works previously mentioned in this article, the benefits provided by this therapy in emotional regulation, reducing anxiety, improving well-being, self-perception, and interpersonal relationships ${ }^{10,24,25}$. This last group of studies is quite peculiar, as it includes experiments that applied a single method of MT (different in each research) to treat different psychiatric disorders. In doing so, each one was able to determine whether a form of application of MT generates positive effects for several disorders at once. Despite this, the small sample size, the high risk of bias, and the lack of well-structured methodologies remain to limit the scientific value of these articles.

Still, the results are relevant. Listening to music routinely is a habit that directly helps regulate emotional states, improves mood, energy to perform activities, and reduces, and reduces tension, acting as self-therapy ${ }^{24,25}$. In contrast, surprisingly, young people with mental health problems sometimes tend to perform this practice in a negative way promoting extreme musical selection - which can lead to the intensification of psychopathological manifestations ${ }^{24}$. In one article, the application of active MT guided by a professional helped the youngsters in the intervention group, at the end of the test, to reduce anxiety and negative symptoms of the various diseases present in the sample ${ }^{24}$.

In another study, a randomized one, a significant sample size of young patients with different psychiatric disorders was submitted to a specific MT model (Alvin model), which included improvisation techniques and listening to musical repertoires created with a professional music therapist ${ }^{10}$. After the 12-week intervention, assessments made at the 13th week showed important improvements in patients' selfesteem, as well as a decrease in depressive symptoms. Despite this, these effects were not, in general, maintained until the 26th week (date of the second evaluation). In addition, there was, in young people aged 13 years old or over, an improvement in communication and interaction skills in the intervention group. In another article, with 
terminally ill patients in a mental health center, the effects of MT were also positive in most participants, mainly to relieve pain and discomfort experienced during hospitalization ${ }^{19}$. Therefore, the use of music adjuvant to psychotherapy is promising and feasible, although studies are still lacking to polish this technique.

\section{LIMITATIONS AND STRENGTHS}

This work has some limitations that may compromise the reliability of the findings. Not using a renowned protocol in its methodology or scales (such as GRADE) to measure the analyzed articles' quality of evidence are examples of this. The small sample size of some articles, as well as the uncertainty of how the patients' diagnoses were established previously, may also influence the results, perhaps emerging inconsistencies when compared to the real use of MT as adjuvant therapy in mentally ill people. Furthermore, the publication period elected as part of the inclusion criteria might have caused important discoveries made before 2016 to be excluded from the analysis, even though this selection intended to limit the review to the most up-to-date findings. Finally, the authors focused on a general view and examination of the MT methods used in each article, without specifically addressing the benefits and harms of each type of technique. Despite this, the main limitation for this work's findings is actually the study design, since reviews (except for systematic reviews with meta-analysis) do not have the capacity of dictating how health professionals should proceed regarding their therapeutic recommendations, only to suggest probable benefits and harms of a certain therapy.

On the other hand, this review, to our knowledge, is one of the few works to simultaneously gather information on the use of MT as an adjuvant therapy in various mental disorders, not limiting its findings to one specific illness. It is also important to note that MT is a new area of study, hence every scientific effort to address its feasibility and efficacy is valid and necessary. At last, considering the lack of studies regarding MT for mental disorders in Brazil - in spite of the country's high rates of mental health issues ${ }^{33}$ - we hope this review serves as an incentive to turn our scientific community's interest towards research on MT and other complementary treatments.

\section{CONCLUSION}

This review analyses previous studies that elucidate the advantages of using MT as an adjunct therapy for the treatment of various mental disorders, which depend on the way it is applied in conjunction with pharmacotherapy and psychotherapy. In addition, we note the specificity of each disease and the ability of musical therapy to stimulate patients with different disorders, if applied in any of its varieties - passive, active, or both - to guarantee results superior to those reached with conservative therapy. New clinical studies, with a larger sample size and greater controlled variables, are required to elucidate which is the best MT technique for each psychiatric disorder. Also, there is a need for systematic reviews with meta-analysis to provide statistical evidence of the MT benefits in psychiatric rehabilitation. There is a lack of studies reporting long-term effects of MT, as well as how and where, anatomically, exposure to MT promotes neurophysiological changes. Despite this, when analyzing the potential for benefits, the analyzed literature suggests that MT does not present worrisome harms and could be used, whenever possible, as an adjuvant therapy to the treatment of mental illnesses.

\section{CONFLICT OF INTEREST}

The authors declare that there is no conflict of interest present in this study.

\section{FINANCING}

The authors declare that there were no sources of funding for this study.

\section{REFERENCES}

1. Definition and quotes about music therapy [Internet]. Silver Spring (MD): American Association of Music Therapy; c1998-2021 [cited 2021 Apr 19]. Available from: https://www.musictherapy.org/about/quotes/

2. Thaut MH, Mclntosh GC. Neurologic music therapy in stroke rehabilitation. Curr Phys Med Rehabil Rep [Internet], 2014 Apr [cited 2021 Apr 19];2: 106-113. Available from:

https://link.springer.com/article/10.1007/s40141-0140049-y

3. McDermott O, Crellin N, Ridder HM, Orrell M. Music therapy in dementia: a narrative synthesis systematic review. Int J Geriatr Psychiatry [Internet], 2013 Aug [cited 2021 Apr 19];28(8): 781-794. Available from: https://pubmed.ncbi.nlm.nih.gov/23080214/

4. Nguyen SA, LAvretsky H. Emerging complementary and integrative therapies for geriatric mental health. Curr Treat Options Psychiatry [Internet]; 2020 Sep [cited 2021 Apr 19];7: 447-470. Available from: https://link.springer.com/article/10.1007/s40501-020$\underline{00229-5}$

5. Hodges DA. Implication of music and brain research: this introductoray article offers an overview of neuromusical research and articulate some basic premises derived from this research. Music Educ $\mathrm{J}$ [Internet], 2000 Sep [cited 2021 Apr 19];87(2): 17-22. Available from: https://journals.sagepub.com/doi/10.2307/3399643

6. World Health Organization. Constitution of the World Health Organization. New York (NY). 1946 Jul. Available from: http://www.direitoshumanos.usp.br/index.php/OMSOrganiza\%C3\%A7\%C3\%A3o-Mundial-daSa\%C3\%BAde/constituicao-da-organizacao-mundialda-saude-omswho.html 
7. Dahms R, Eicher C, Haesner M, Mueller-Werdan U. Influence of music therapy and music-based Interventions on dementia: a pilot study. J Music Ther [Internet], 2021 May [cited 2021 Jul 10];XX(XX): 1-25. Available from: https://academic.oup.com/jmt/advancearticle/doi/10.109 3/jmt/thab005/6265007

8. Silva LK, Brito TSS, Souza LAPS, Luvizutto GJ. Musicbased therapy in Parkinson's disease: an approach based on international classification of functioning, disability and health. J Bodyw Mov Ther [Internet], 2021 April [cited 2021 Jul 10];26: 524-529. Available from: https://www.bodyworkmovementtherapies.com/article/S 1360-8592(20)30168-6/fulltext\#articlelnformation

9. Geipel J, Koenig J, Hillecke TK, Resch F, Kaess M. Music-based intervention to reduce internalizing symptoms in children and adolescents: a meta-analysis. J Affect Disord [Internet], 2018 Jan [cited 2021 Jul 10];225: 647-656. Available from: https://www.sciencedirect.com/science/article/abs/pii/S0 165032716316585?via\%3Dihub

10. Porter S, McConnell T, McLaughlin K, Lynn F, Cardwell C, Braiden HJ, Boylan J, Holmes V. Music therapy for children and adolescents with behavioural and emotional problems: a randomised controlled trial. J Child Psychol Psychiatry [Internet]. 2017 Oct [cited 2021 Apr 19]; 58(5): 586-594. Available from: https://acamh.onlinelibrary.wiley.com/doi/full/10.1111/jc pp.12656

11. Mays KL, Clark DL, Gordon AJ. Treating addiction with tunes: a systematic review of music therapy for the treatment of patients with addictions. Subst Abus [Internet]. 2008 Dec [cited 2021 Jul 10];29(4): 51-59. Available

from: https://www.tandfonline.com/doi/abs/10.1080/08897070 $\underline{802418485}$

12. Sigurdardóttir GA, Nielsen PM, Rønager J, Wang AG. A pilot study on high amplitude low frequency-music impulse stimulation as an add-on treatment for depression. Brain Behav [Internet]. 2019 Oct [cited 2021 Apr 19]; 9(10): e01399. Available from: https://onlinelibrary.wiley.com/doi/full/10.1002/brb3.139 $\underline{9}$

13. Feng $K$, Shen $C Y$, Ma $X Y$, Chen GF, Zhang ML, Xu B, Liu XM, Sun JJ, Zhang XQ, Liu PZ, Ju Y. Effects of music therapy on major depressive disorder: a study of prefrontal hemodynamic functions using fNIRS. Psychiatry Res [Internet]. 2019 Mar [cited 2021 Apr 19]; 275: 86-93. Available from: https://www.sciencedirect.com/science/article/abs/pii/S0 165178118322212?via\%3Dihub
14. Feldman JM, Matte L, Interian A, Lehrer PM, Lu SE, Scheckner B, Steinberg DM, Oken T, Kotay A, Sinha S, Shim C. Psychological treatment of comorbid asthma and panic disorder in Latino adults: Results from a randomized controlled trial. Behav Res Ther [Internet]. 2016 Dec [cited 2021 Apr 19]; 87: 142-154. Available from:

https://www.sciencedirect.com/science/article/abs/pii/S0 005796716301644?via\%3Dihub

15. Pezzin LE, Larson ER, Lorber W, McGinley EL, Dillingham TR. Music-instruction intervention for treatment of post-traumatic stress disorder: a randomized pilot study. BMC Psychol [Internet]. 2018 Dec [cited 2021 Apr 19];6(1): 60. Available from: https://pubmed.ncbi.nlm.nih.gov/30567598/

16. Lazarov A, Pine DS, Bar-Haim Y. Gaze-contingent music reward therapy for social anxiety disorder: a randomized controlled trial. Am J Psychiatry [Internet]. 2017 Jan [cited 2021 Apr 19];174(7): 649-656. Available from:

https://ajp.psychiatryonline.org/doi/pdf/10.1176/appi.ajp. $\underline{2016.16080894}$

17. Sewak R, Spielholz NI. Relapse prevention: using sound to reduce the probability of recidivism and suffering following detoxification. Med Hypotheses [Internet]. 2018 Sep [cited 2021 Apr 19];118: 84-91. Available from: https://www.sciencedirect.com/science/article/abs/pii/S0 306987718303529?via\%3Dihub

18. Mathis WS, Han X. The acute effect of pleasurable music on craving for alcohol: a pilot crossover study. J Psychiatr Res [Internet]. 2017 Jul [cited 2021 Apr 19];90: 143-147. Available from: https://www.sciencedirect.com/science/article/abs/pii/S0 022395616306264?via\%3Dihub

19. Porter S, McConnell T, Graham-Wisener L, Regan J, McKeown M, Kirkwood J, Clarke M, Gardner E, Dorman S, McGrillen K, Reid J. A randomized controlled pilot and feasibility study of music therapy for improving the quality of life of hospice inpatients. BMC Palliat Care [Internet]. 2018 Nov [cited 2021 Apr 19]; 17:125. Available from: https://bmcpalliatcare.biomedcentral.com/articles/10.11 86/s12904-018-0378-1

20. Kaelen M, Giribaldi B, Raine J, Evams L, Timmerman C, Rodriguez N, Roseman L, Feilding A, Nutt D, Carhart-Harris R. The hidden therapist: evidence for a central role of music in psychedelic therapy. Psycopharmacology [Internet]. 2018 Feb [cited 2021 Apr 19]; 235: 505-519. Available from: https://link.springer.com/article/10.1007/s00213-0174820-5 
21. Hirschberg R, Sylvia LG, Wright EC, Gupta CT, McCarthy MD, Harward LK, Goetter EM, Boland H, Tanev K, Spencer TJ. Collaborative songwriting intervention for veterans with post-traumatic stress disorder. J Altern Complement Med [Internet]. 2020 Jan [cited 2021 Apr 19];26(3): 198-203. Available from: https://pubmed.ncbi.nIm.nih.gov/31985263/

22. Jeon GS, Gang M, Oh K. The effectiveness of the Nanta-program on psychiatric symptoms, interpersonal relationships, and quality of life in forensic inpatients with schizophrenia. Arch Psychiatr Nurs [Internet]. 2017 Feb [cited 2021 Apr 19];31(1): 93-98. Available from: https://www.psychiatricnursing.org/article/S08839417(16)30221-7/fulltext

23. Taets GGC, Jomar RT, Abreu AMM, Capella MAM. Effect of music therapy on stress in chemically dependent people: a quasi-experimental study. Rev Latino-Am Enfermagem [Internet]. 2019 Jan [cited 2021 Apr 19];27: e3115. Available from: https://www.scielo.br/scielo.php?script=sci arttext\&nrm =iso\&lng=pt\&tIng=pt\&pid=S0104-11692019000100303

24. Archambault K, Vaugon K, Deumié V, Brault M, Perez RM, Peyrin J, Vaillancourt G, Garel P. MAP: a personalized receptive music therapy intervention to improve the affective well-being of youths hospitalized in a mental health unit. J Music Ther [Internet]. 2019 Winter;56(4):381-402. Available from: https://academic.oup.com/jmt/article/56/4/381/5631978

25. Gebhardt S, Dammann I, Loescher K, Wehmeier PM, Vedder H, Georgi RV. The effects of music therapy on the self and emotions - an interim analysis. Complement Ther Med [Internet]. 2018 Dec [cited 2021 Apr 19];41: 61-66. Available from: https://www.sciencedirect.com/science/article/abs/pii/S0 96522991830205X?via\%3Dihub

26. D'abreu L. The challenge of making a psychiatric diagnosis in children. Contextos Clinic [Internet], 2012 Jul [cited 2021 Apr 19];5(1): 2-9. Available from: http://pepsic.bvsalud.org/scielo.php?script=sci arttext\& pid $=$ S1983-34822012000100002

27. Amarante $P$, Nunes MO. Psychiatric reform in the SUS and the struggle for a society without asylums. Ciênc. saúde coletiva [Internet]. 2018 Jun [cited 2021 Apr 19];23(6): 2067-2074. Available from: https://www.scielo.br/scielo.php?pid=S1413$\underline{81232018000602067 \& \text { script }=\text { sci abstract\&tlng }=p t}$

28. Esteves FC, Galvan AL. Depressão numa contextualização contemporânea. Aletheia [Internet]. 2006 Dec [cited 2021 Jul 08]; (24): 127-135. Available from:

http://pepsic.bvsalud.org/scielo.php?script=sci arttext\& pid=S1413-03942006000300012\&lng=pt
25. Hirano, J, Takamiya A, Yamagata B, Hotta S, Miyasaka Y, Pu S, Iwanami A, Uchida H, Mimura M. Frontal and temporal cortical functional recovery after electroconvulsive therapy for depression: a longitudinal functional near-infrared spectroscopy study. J. Psychiatr. Res [Internet]. 2019 Feb [cited 2021 Apr 19]; 91: 26-35. Available from: https://pubmed.ncbi.nlm.nih.gov/28292650/

26. Bryant RA, Sackville T, Dang ST, Moulds M, Guthrie R. Treating acute stress disorder: an evaluation of cognitive behavior therapy and supportive counseling techniques. Am J Psychiatry [Internet]. 1999 Nov [cited 2021 Apr 19];156(11):1780-1786. Available from: https://ajp.psychiatryonline.org/doi/full/10.1176/ajp.156. $\underline{11.1780}$

27. National Institute of Mental Health. Social Anxiety Disorder: More Than Just Shyness [Internet]. Bethesda, MD: National Institute of Mental Health; 2016 [cited 2021 Jul 08]. Available from: https://www.nimh.nih.gov/health/publications/socialanxiety-disorder-more-than-just-shyness/

32. American Psychiatric Association. What Is Schizophrenia? [Internet]. Washington, DC: American Psychiatric Association; 2020 [cited 2021 Jul 08]. Available from: https://www.psychiatry.org/patientsfamilies/schizophrenia/what-is-schizophrenia

33. Almeida-Filho N, Jesus MJD, Coutinho E, França JF, Fernandes J, Andreoli SB, et al. Brazilian multicentric study of psychiatric morbidity: methodological features and prevalence estimates. Brit J Psychiat [Internet]. 2018 Jan [cited 2021 Jul 10];171(6):524-9. Available from: https://www.cambridge.org/core/journals/thebritish-journal-of-psychiatry/article/abs/brazilianmulticentric-study-of-psychiatricmorbidity/FF15BE894BBE8DB9437920745D36876B 